\title{
Effect Of Chinese Herb Danzhi Xiaoyao Pills On Pharmacokinetics Of Venlafaxine In Beagles
}

This article was published in the following Dove Press journal:

Drug Design, Development and Therapy

\section{Yong-liang Zhu \\ Shuang-long Li (D) \\ Ke-li Chen \\ Kun-peng Ma \\ De-qian Wu \\ Xiang-jun Qiu}

Medical College of Henan University of Science and Technology, Luoyang 471023, People's Republic of China

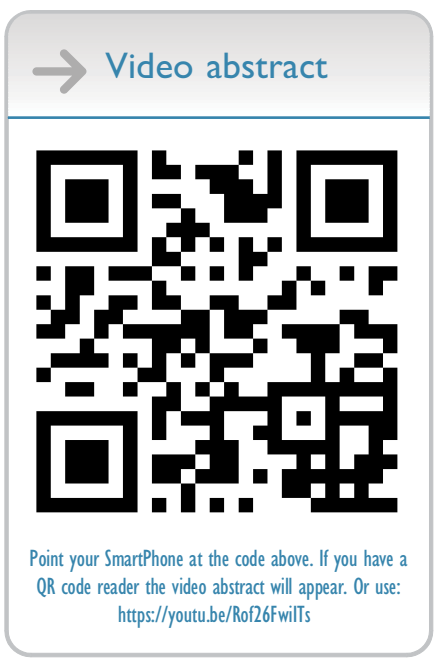

Correspondence: Xiang-jun Qiu Medical College of Henan University of Science and Technology, Luoyang 471023, People's Republic of China

Email lyxiangjun@126.com
Objective: To investigate the effects of Chinese herb Danzhi Xiaoyao pills on the pharmacokinetics of venlafaxine and its metabolites O-desmethylvenlafaxine (ODV) and N-desmethylvenlafaxine (NDV) in beagles by using ultra-performance liquid chromatography-tandem mass spectrometry (UPLC-MS/MS).

Methods: Six beagles (half male, half female) were chosen to test, being fasted before the experiment but having free access to drinking water 1 day before being fed drugs. After oral administration of venlafaxine hydrochloride tablets $(10.28 \mathrm{mg} / \mathrm{kg})$, the blood samples were collected in succession at different points in time. After 1-week washout period, Danzhi Xiaoyao pills $(0.6 \mathrm{~g} / \mathrm{kg})$ were given through oral administration to the six beagles every morning until the 7 th day, venlafaxine hydrochloride tablets $(10.28 \mathrm{mg} / \mathrm{kg})$ were given after feeding Danzhi Xiaoyao pills $(0.6 \mathrm{~g} / \mathrm{kg})$ half an hour and blood samples were collected continuously at different points. All samples were analyzed by UPLC-MS/MS, and the main pharmacokinetic parameters of venlafaxine, ODV and NDV were computed by DAS 2.0.

Results: The $\mathrm{C}_{\max }$ of the venlafaxine group (control group) and the combination group (experimental group) were $(2267.26 \pm 252.89) \mathrm{ng} / \mathrm{mL}$ and $(1542.64 \pm 190.73) \mathrm{ng} / \mathrm{mL}$, respectively. The $\mathrm{AUC}_{(0-\infty)}$ of the two groups were $(13,934.79 \pm 3609.23) \mathrm{ng} \cdot \mathrm{h} / \mathrm{mL}$ and $(8001.91 \pm 2167.58) \mathrm{ng} \cdot \mathrm{h} / \mathrm{mL}$, respectively. The ODV $\mathrm{C}_{\max }$ of the two groups were $(2253.80 \pm 215.81) \mathrm{ng} / \mathrm{mL}$ and $(2721.37$ $\pm 118.20) \mathrm{ng} / \mathrm{mL}$, and $\mathrm{AUC}_{(0-\infty)}$ were $(13,974.99 \pm 2784.04) \mathrm{ng} \cdot \mathrm{h} / \mathrm{mL}$ and $(17,539.44 \pm 1894.29)$ $\mathrm{ng} \cdot \mathrm{h} / \mathrm{mL}$, respectively. The NDV $\mathrm{C}_{\max }$ of the two groups were $(50.98 \pm 5.76) \mathrm{ng} / \mathrm{mL}$ and $(58.74$ $\pm 12.33) \mathrm{ng} / \mathrm{mL}$, and $\mathrm{AUC}_{(0-\infty)}$ were $(179.26 \pm 34.94) \mathrm{ng} \cdot \mathrm{h} / \mathrm{mL}$ and $(220.68 \pm 51.41) \mathrm{ng} \cdot \mathrm{h} / \mathrm{mL}$, respectively. After administration of Danzhi Xiaoyao pills, the $\mathrm{C}_{\max }$ and $\mathrm{AUC}_{(0-\infty)}$ of venlafaxine decreased significantly, indicating that the plasma exposure of venlafaxine decreased. The increase of $\mathrm{C}_{\max }$ and $\mathrm{AUC}_{(0-\infty)}$ of ODV and NDV indicated a rise in plasma exposure.

Conclusion: Danzhi Xiaoyao pills can accelerate the metabolism of venlafaxine in beagles. In clinical, when venlafaxine was co-administrated with Danzhi Xiaoyao pills, dose adjustment of venlafaxine should be taken into account.

Keywords: beagle, UPLC-MS/MS, Danzhi Xiaoyao pills, venlafaxine, ODV, NDV, drugdrug interaction

\section{Introduction}

Depressive disorder, also known as major depressive disorder, is one of the symptoms of depression, anxiety, cognitive impairment, hallucination and suicide. ${ }^{1}$ According to the World Psychiatric Association (WPA), this disease has become the fourth largest disease in the world and will be the second largest by $2020 .^{2,3}$ Venlafaxine hydrochloride (venlafaxine, molecular formula: $\mathrm{C}_{17} \mathrm{H}_{27} \mathrm{NO}_{2} \cdot \mathrm{HCl}$ ) is an important drug for clinical treatment of depression, which was approved by the US Food and Drug Administration (FDA) in 1993 and was the first SNRI (serotonin-norepinephrine 
reuptake inhibitor) for the treatment of major depressive disorder in adults, ${ }^{4}$ mainly by inhibiting serotonin (5-HT) and norepinephrine (NE) reuptake dual function. ${ }^{5,6}$ Finally, metabolism is deactivated under the action of cytochrome P450 in liver, and the main metabolite is O-desmethylvenlafaxine (ODV, molecular formula: $\mathrm{C}_{16} \mathrm{H}_{25} \mathrm{NO}_{2}$ ), which is catalyzed by CYP2D6, ${ }^{7}$ while the minor metabolite is $\mathrm{N}$ desmethylvenlafaxine (NDV), which is catalyzed by CYP3A4. ${ }^{8}$ Both metabolites are eventually metabolized to $\mathrm{N}$, O-didesmethylvenlafaxine (DDV), which is possibly catalyzed by CYP2D6. ${ }^{9}$ Venlafaxine is a new kind of phenylethylamine antidepressant drug, ${ }^{2}$ and its molecular structure (A), ODV structure (B) and NDV structure (C) are shown in Figure 1. Meanwhile, the structure of Diazepam (D) which was regarded as IS is also shown in Figure 1.

Danzhi Xiaoyao pill is a classical traditional Chinese medicine, which had been recorded in Jiaozhu Furen Liangfang "Edited and Commented Effective Formulae for Woman” written by Xue Yi (1487-1559) since the Ming Dynasty, ${ }^{3}$ to treat the liver stagnation and qi stagnation, ${ }^{10}$ and its composition and dose of the prescription are listed in Figure 2. In recent years, many studies have shown that Danzhi Xiaoyao pills have an excellent effect on the treatment of depression. ${ }^{11-13}$ According to Chinese medicinal theory, Danzhi Xiaoyao pills take effect by regulating qi

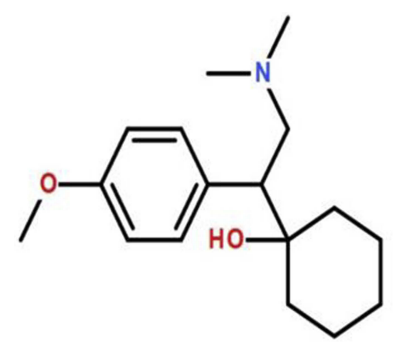

A

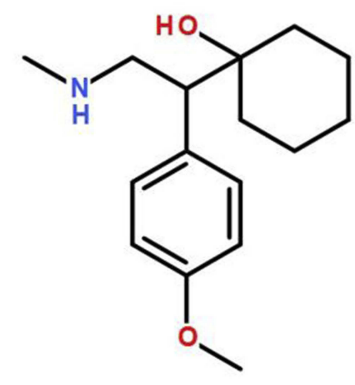

C

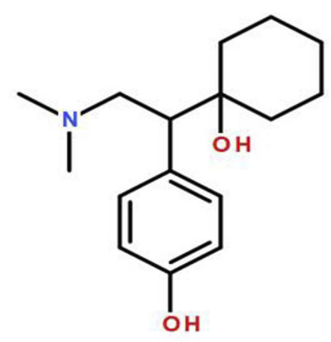

B

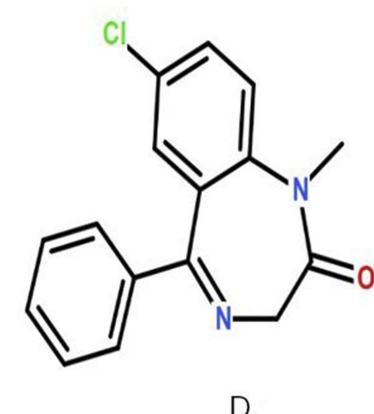

Figure I The chemical structure of venlafaxine (A), ODV (B), NDV (C), diazepam (D). and blood, soothing liver-qi stagnation and adjusting the function of internal organs, ${ }^{14}$ however, due to the complex components of traditional Chinese medicine, it is still not clear what the main mechanism of action of its drugs is, which requires further researches in the later stage.

Nowadays, the combination of traditional Chinese medicine (TMC) and venlafaxine has been well applied to clinical practice. ${ }^{15,16}$ The combination method can not only reduce the side effects of western medicines, ${ }^{17}$ but also enhance the therapeutic effect. ${ }^{3,13,18}$ Clinically, Danzhi Xiaoyao pill and venlafaxine are commonly used in the treatment of depression. ${ }^{19,20}$ But most studies have focused on using HPLC methods to determine venlafaxine and its main active metabolite ODV in human plasma. ${ }^{6,21}$ There is no relevant research showing the effect of Danzhi Xiaoyao pill on the metabolism of venlafaxine. Therefore, we selected six healthy beagles and compared the pharmacokinetic differences between control groups (venlafaxine hydrochloride tablets) and experimental groups (venlafaxine hydrochloride tablets after 7 days of oral administration of Danzhi xiaoyao pills) to study the effect of Danzhi Xiaoyao pill on the pharmacokinetics of venlafaxine and its metabolites (ODV and NDV) in beagles, using the UPLC-MS/MS method.

\section{Materials And Methods}

\section{Animals}

Six beagles (half male, half female, $5 \sim 6 \mathrm{~kg}$ ) were supported by the Laboratory Animal Center of Henan University of Science and Technology (Luoyang, China). They were housed in a room at $16 \sim 28^{\circ} \mathrm{C}$, with a $12 / 12-\mathrm{hr}$ light/dark cycle, 40\% 70\% humidity and were fed twice every day, free access to water. All beagles were forbidden to eat $12 \mathrm{hrs}$ before the experiment, but could drink freely. The animals were authorized by Animal Ethics Committee of Henan University of Science and Technology and also were cared on the basis of the National Institutes of Health Guide for the Care and Use of Laboratory Animals.

\section{Chemicals Materials}

Venlafaxine hydrochloride tablets (batch number: 180508) were acquired from Changzhou Siyao Pharmaceuticals Co., Ltd (Changzhou, China). Danzhi Xiaoyao pills (batch number: 280827) were obtained from Kunming Pharmaceutical Corp. (Kunming, China). Venlafaxine (purity $>99 \%$, batch number: 100543-200401) were bought from National Institutes for Food and Drug Control. (Beijing, China). ODV (purity 
A

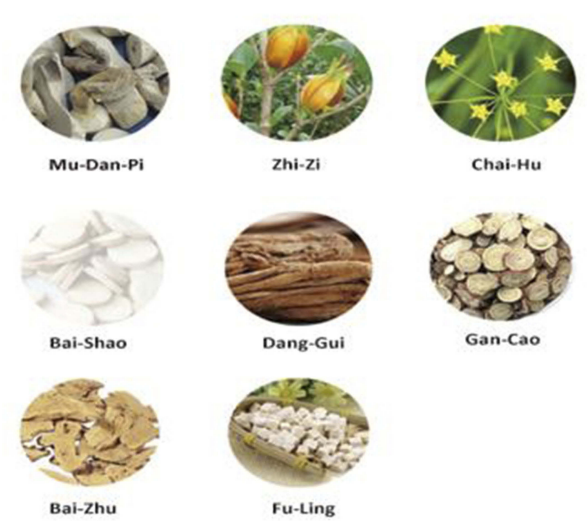

B

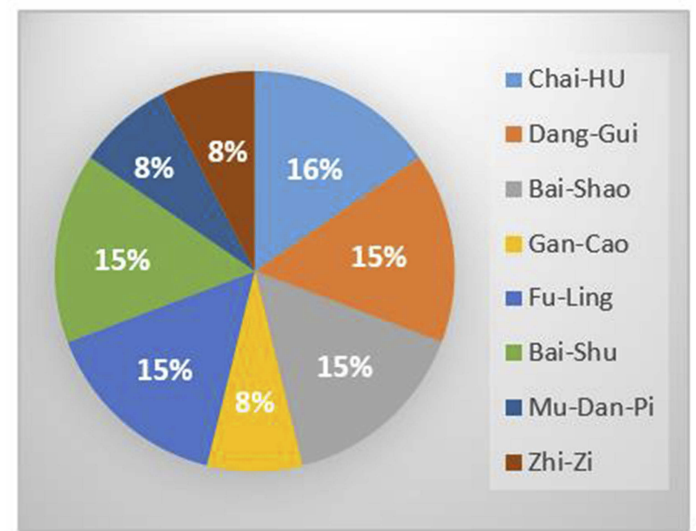

C

\begin{tabular}{|l|l|l|l|}
\hline Botanical name & Herbal name & Chinese name & Ratio in DZXY \\
\hline Paeonia suffruticosa Andr & Moutan Cortex & Mu-Dan-Pi & $8 \%$ \\
\hline Gardenia jasminoides & Gardeniae Fructus & Zhi-Zi & $8 \%$ \\
\hline Bupleurum chinese DC & Bupleuri Radix & Chai-Hu & $16 \%$ \\
\hline Paeonia lactiflora Pall & Paeoniae Radix Alba & Bai-Shao & $15 \%$ \\
\hline Angelica sinensis (Oliv.) Diels & Angelicae Sinensis Radix & Dang-Gui & $15 \%$ \\
\hline Glycyrrhiza uralensis Fish & Glycyrrhizae Radix Et Rhizoma & Gan-Cao & $8 \%$ \\
\hline Atractylodes macrocephala Koidz & Atractylodis Macrocephalae Rhizoma & Bai-Zhu & $15 \%$ \\
\hline Poria cocos (Schw.) Wolf & Poria & Fu-Ling & $15 \%$ \\
\hline
\end{tabular}

Figure 2 Information of components in Danzhi Xiaoyao pill (DZXY). (A) Figures of herbs in DZXY. (B) Ratio of each herb in DZXY. (C) List of accepted Botanical, Herbal and Chinese name of the corresponding herb in DZXY according to www.theplantlist.org.

$>98 \%$, batch number: M1223A) was bought from Dalian Meilun Biotechnology Co., Ltd (Dalian, China). NDV (purity $>97 \%$, batch number: 9-JWA-51-1) was provided by Chem Strong Scientific Co., Ltd (Shenzhen, China). Diazepam (purity $>98 \%$, batch number: 1230-9601) was supplied by National Narcotics Laboratory (Beijing, China) and used as the internal standard (IS). A water purification system (Milli-Q academic reagent grade, Millipore, Bedford, USA) was used to prepare deionized water. Acetonitrile and methanol of liquid chromatography (LC) grade were acquired from Merck Company (Darmstadt, Germany). All other reagents were of analytical grade or better.

\section{Instrumentation And Conditions}

The Acquity ultra-performance liquid chromatography (UPLC, Waters Corp., Milford, MA, USA) system was used for analysis. Separation by chromatography was achieved by an Acquity BEH C18 column $(2.1 \mathrm{~mm} \times 50 \mathrm{~mm}$, $1.7 \mu \mathrm{m})$ at $45^{\circ} \mathrm{C}$. The gradient elution solutions were water with $0.1 \%$ formic acid (A) and acetonitrile (B). The following gradient protocol was used: $0-0.5$ mins $(90-90 \%$ A), $0.5-$ 1.0 mins (90-10\% A), 1.0-2.0 mins (10-10\% A), 2.0-2.1 mins (10-90\% A), $2.1-3.0 \min (90-90 \%$ A). The total run time was set at $3.0 \mathrm{mins}$ and $0.40 \mathrm{~mL} / \mathrm{min}$ was the flow rate.

Mass spectrometric measurement was achieved on a XEVO TQ-S triple quadrupole mass spectrometer with an electrospray ionization (ESI) interface in positive ionization mode. Quantification was achieved by multiple reaction monitoring (MRM) mode with transitions of $\mathrm{m} / \mathrm{z}$ $278.1 \rightarrow 58.1$ for venlafaxine, $\mathrm{m} / \mathrm{z} 264.2 \rightarrow 58.1$ for $\mathrm{ODV}, \mathrm{m} / \mathrm{z} 264.2 \rightarrow 147.0$ for $\mathrm{NDV}$ and $\mathrm{m} / \mathrm{z} 285.0 \rightarrow$ 154.0 for IS, respectively. Data acquisition and control of instrument were done by Masslynx 4.1 software (Waters Corp., Milford, MA, USA).

\section{Standard Solutions, Calibration Standards, And Quality Control (QC) Samples}

The standard venlafaxine solution $(1 \mathrm{mg} / \mathrm{mL})$ was obtained by accurately weighing $10 \mathrm{mg}$ of standard venlafaxine in a $10-\mathrm{mL}$ 
volumetric flask and dissolving it with methanol to a constant volume of $10 \mathrm{~mL}$. The ODV reserve solution $(1 \mathrm{mg} / \mathrm{mL})$ was obtained by accurately weighing $1 \mathrm{mg}$ and adding $1 \mathrm{~mL}$ methanol in a 2-mL EP tube. The NDV reserve solution ( $1 \mathrm{mg} / \mathrm{mL}$ ) was also obtained by accurately weighing $1 \mathrm{mg}$ and adding $1 \mathrm{~mL}$ methanol in a $2-\mathrm{mL}$ EP tube. The standard substance of diazepam, $25 \mathrm{mg}$, was accurately weighed in a $25-\mathrm{mL}$ volumetric flask, dissolved in methanol and then in a constant volume to $25 \mathrm{~mL}$. The final concentration was $1 \mathrm{mg} / \mathrm{mL}$, which was diluted with acetonitrile to form an internal standard working solution with a concentration of 50 $\mathrm{ng} / \mathrm{mL}$. All solution samples were stored at $4^{\circ} \mathrm{C}$.

\section{Study Design}

Six beagles were given venlafaxine hydrochloride tablets $(10.28 \mathrm{mg} / \mathrm{kg})$ through oral administration and then given normal saline (NS, 10 20 mL) immediately through gavage administration; the blood samples $(2 \mathrm{~mL})$ were collected from foreleg vein or hind vein into heparinized polythene tubes at $0.33,0.67,1,1.5,2,3,4,6,8,12,24$ and 36 hrs. All samples were centrifuged at $10,000 \times \mathrm{g}$ for $10 \mathrm{mins}$. The acquired plasma $(100 \mu \mathrm{L})$ was saved at $-20^{\circ} \mathrm{C}$ until the test. After the 1-week washout period, six beagles were given Danzhi Xiaoyao pills $(0.6 \mathrm{~g} / \mathrm{kg})$ through oral administration in the everyday morning until the 7 th day, giving venlafaxine hydrochloride tablets $(10.28 \mathrm{mg} / \mathrm{kg})$ after feeding Danzhi Xiaoyao pills for half an hour. The blood samples $(2 \mathrm{~mL})$ were also collected from foreleg vein or hind vein into heparinized polythene tubes at the same point in time and were handled with the same conditions.

\section{Method Validation}

Before using this method to confirm venlafaxine, ODV and NDV in plasma, the method was totally validated for specificity, linearity, precision, accuracy, recovery, and stability. The UPLC-MS/MS method in this experiment was validated according to the United States Food and Drug Administration (FDA) guidelines. ${ }^{22}$

\section{Preparation Of Samples}

Samples were prepared by protein precipitation. In brief, $10 \mu \mathrm{L}$ IS working solution $(50 \mathrm{ng} / \mathrm{mL})$ was added to $50 \mu \mathrm{L}$ plasma in a $1.5-\mathrm{mL}$ Eppendorf tube and followed by vortexing for $15 \mathrm{~s}$. The mixture was precipitated by addition of $200 \mu \mathrm{L}$ acetonitrile and then vortexed for $1 \mathrm{~min}$. Finally, the plasma was centrifuged at $15,000 \times \mathrm{g}$ for 15 mins to obtain the supernatant, and a $2 \mu \mathrm{L}$ supernatant was injected for analysis by the UPLC-MS/MS system.

\section{Specificity}

To estimate the methodological specificity, three groups samples were chosen to be analysed by the UPLC-MS/ MS. A blank plasma which included venlafaxine, ODV and NDV standard substance (a). A blank plasma with internal standard substance (b). A plasma collected after oral administration of venlafaxine hydrochloride tablets after $2 \mathrm{hrs}$ (c). All plasma samples were collected from beagles. The three groups samples chromatograms were compared to judge the existence of endogenous substances in plasma.

\section{Linearity}

Concentration of venlafaxine for $1,5,10,50,100,500$, 1000, $2000 \mathrm{ng} / \mathrm{mL}$, concentration of ODV for 1, 5, 10, 50, $100,500,1000,2000 \mathrm{ng} / \mathrm{mL}$ and concentration of NDV for $0.1,0.5,1,5,10,50,100,200 \mathrm{ng} / \mathrm{mL}$ were prepared, and after treatment, the linearity of each standard calibration curve was computed by plotting the peak areas rations (Ai/As) versus concentration of analytes.

\section{Precision And Accuracy}

The plasma solutions of venlafaxine $(2.5,100,1500 \mathrm{ng} /$ $\mathrm{mL}), \operatorname{ODV}(2.5,100,1500 \mathrm{ng} / \mathrm{mL})$ and $\operatorname{NDV}(0.25,10$, $150 \mathrm{ng} / \mathrm{mL}$ ) at low, medium and high concentrations (6 portions at each concentration) were prepared and then were processed before entering the chromatographic system for detection. In the same day, the intra-day precision was calculated. Standard curves were measured and followed for 3 consecutive days to calculate the inter-day precision.

\section{Recovery And Matrix Effects (ME)}

Venlafaxine $(2.5,100,1500 \mathrm{ng} / \mathrm{mL}), \operatorname{ODV}(2.5,100,1500 \mathrm{ng} /$ $\mathrm{mL})$ and $\operatorname{NDV}(0.25,10,150 \mathrm{ng} / \mathrm{mL})$ plasma reference solutions at low, medium and high concentrations were prepared, and 6 samples were prepared in parallel for each concentration, and then the peak area(A) was obtained after treatment. The supernatant was taken from 6 portions of blank beagle plasma, and the peak area (B) was obtained by adding three matrix reference substances with the same concentration as the theoretical sample injection of quality control samples. The ratio of $\mathrm{A}$ to $\mathrm{B}$ was the extraction recovery rate of the above three mass concentrations, and the extraction recovery rate of the internal standard was calculated by the same method.

The blank plasma was replaced by pure water, and the peak area (C) was obtained by adding three matrix reference substances with the same concentration as that in 
the quality control sample theory. The ME of venlafaxine, ODV, NDV and internal standard were computed with $\mathrm{B} / \mathrm{C} \times 100 \%$.

\section{Stability}

To test the plasma stability of venlafaxine, ODV and NDV, three different concentrations $(2.5,100,1500 \mathrm{ng} / \mathrm{mL}$ for venlafaxine, $2.5,100,1500 \mathrm{ng} / \mathrm{mL}$ for ODV and $0.25,10$, $150 \mathrm{ng} / \mathrm{mL}$ for NDV) were disposed. Each sample was prepared 6 portions and tested the stability in 4 conditions: room temperature for $4 \mathrm{hrs}, 4^{\circ} \mathrm{C}$ for $24 \mathrm{hrs}$, three cycles of freezing and thawing $\left(-20 \sim 25^{\circ} \mathrm{C}\right), 4$ weeks storage at $-20^{\circ} \mathrm{C}$.

\section{Plasma Sample Detection}

The concentrations of the three substances in all samples were tested by the method established in this experiment. For samples with a concentration higher than the upper limit of the standard curve, the samples were diluted with blank plasma and tested, and the drug concentration was calculated according to the dilution factor.

\section{Statistical Analysis}

The drug concentration data of plasma were processed by DAS (Drug And Statistics, version 2.0) and then were expressed as mean \pm SD. Meanwhile, the group data were analyzed to make the Independent-Samples $T$ Test by SPSS 20.0. P values less than 0.05 were considered statistical difference, and $\mathrm{P}$ values less than 0.01 were considered statistically significant difference.

\section{Results}

\section{Specificity}

As Figure 3 shows, the chromatographic peaks of venlafaxine, ODV, NDV and IS in plasma were well separated. Endogenous substances in plasma did not interfere with the determination of analytes and IS. The retention times of venlafaxine, ODV, NDV and IS were 1.2, 1.08, 1.15 and $1.44 \mathrm{~min}$, respectively. The chromatographic peak shape was better and the baseline was stable, meaning that the method had a high specificity.

\section{Linearity}

Linearity for each analyte was established over the concentration range of $0.25-1500 \mathrm{ng} / \mathrm{mL}$. The typical regression equations and correlation coefficient were as follows: $\mathrm{y}=$ $0.0168 \mathrm{x}+0.0643, \mathrm{r}=0.9993$ for venlafaxine, $y=0.0178 x$ $0.0381, \mathrm{r}=0.9994$ for ODV, and $y=0.0214 x+0.0162, \mathrm{r}=$
0.999 3, respectively. The lower limit of quantification (LLOQ) was $1 \mathrm{ng} / \mathrm{mL}$ for venlafaxine, $1 \mathrm{ng} / \mathrm{mL}$ for ODV, and $0.1 \mathrm{ng} / \mathrm{mL}$ for NDV, respectively.

\section{Precision And Accuracy}

The low, medium and high quality concentrations of venlafaxine, ODV and NDV were prepared at 2.5, $100,1500 \mathrm{ng} / \mathrm{mL}, 2.5,100,1500 \mathrm{ng} / \mathrm{mL}$ and $0.25,10$, $150 \mathrm{ng} / \mathrm{mL}$, respectively. Each of the concentrations was prepared by 6 sections and entered into the UPLC-MS/MS chromatographic system for detection after processing. In the same day, the intra-day precision was calculated. Interday precision was calculated by measuring and following the standard curve for 3 consecutive days. The results are shown in Table 1.

\section{Recovery And ME}

Table 2 shows the recoveries and ME at low, medium and high concentrations of venlafaxine, ODV and NDV. The recoveries rang of three substances were $80.53 \pm 2.39 \% \sim 98.48 \pm 2.96 \%$ $(\mathrm{RSD}<15 \%, \mathrm{n}=6)$, while IS ( $50 \mathrm{ng} / \mathrm{mL}$ ) was $91.03 \pm 5.88 \%$ $(\mathrm{RSD}=6.46 \%, \mathrm{n}=6)$. At the same time, the ME rang of three substances was $98.91 \pm 2.46 \% \sim 101.88 \pm 3.11 \%$ (RSD $<15 \%$, $\mathrm{n}=6$ ), which indicated that the ME did not affect the determination of three substances.

\section{Stability}

Tables $3-5$ shows the stability for venlafaxine, ODV and NDV in 4 different storage and temperature conditions. The RE of samples all ranged from $-8.13 \%$ to $4.27 \%$. It indicated that concentrations of three substances in beagle plasma samples were stable under the above four preservation conditions, and no significant degradation was observed.

\section{Pharmacokinetics Of Venlafaxine, ODV And NDV}

After the beagles were given venlafaxine hydrochloride tablets alone, and combining with venlafaxine hydrochloride tablets and Danzhi Xiaoyao pills, the average plasma drug concentration-time curves of venlafaxine are shown in Figure 4, and the average plasma drug concentration-time curves of its metabolites (ODV, NDV) in plasma are shown in Figures 5-6, respectively. DAS 2.0 was used for analysis and processing. Meanwhile, Tables $6-8$ show the pharmacokinetic parameters of three substances, respectively. 
Compared with control groups, the experimental groups' results showed that the $t_{1 / 2}$ of venlafaxine was mildly decreased by $24.83 \%$, which indicated that the metabolism was accelerated in the experimental groups. $\mathrm{AUC}_{(0-\mathrm{t})}$ and $\mathrm{AUC}_{(0-\infty)}$ of venlafaxine were also decreased by $42.39 \%$ and $42.57 \%$, respectively, and the $\mathrm{C}_{\max }$ was decreased by $31.96 \%$. In addition, the $\mathrm{T}_{\max }$ was significantly declined by $46.39 \%$, while the $\mathrm{CLz} / \mathrm{F}$ was sharply increased by $73.68 \%$. All figures showed that after the combined administration of Danzhi Xiaoyao pills, the plasma exposure of venlafaxine decreased. After the combined administration of Danzhi Xiaoyao pills, the $\mathrm{AUC}_{(0-\mathrm{t})}$ and $\mathrm{AUC}_{(0-\infty)}$ of ODV were increased by $25.68 \%$ and $25.51 \%$, respectively. Meanwhile, the $\mathrm{C}_{\max }$ of ODV had an opposite trend compared to $\mathrm{C}_{\max }$ of venlafaxine, jumped by $20.75 \%$, which indicated that the plasma exposure of ODV increased. As for NDV, the trend was similar to ODV. $\mathrm{AUC}_{(0-\mathrm{t})}$ and $\mathrm{AUC}_{(0-\infty)}$ were also increased by $21.91 \%$ and $23.11 \%$, respectively.

\section{Discussion}

At present, there are a number of methods to analyze the active metabolite in plasma such as HPLC, ${ }^{23}$ HPLCPDA, ${ }^{24}$ RP-HPLC, ${ }^{25}$ etc. But according to the reports, this method has a low sensitivity, narrow linear range

A
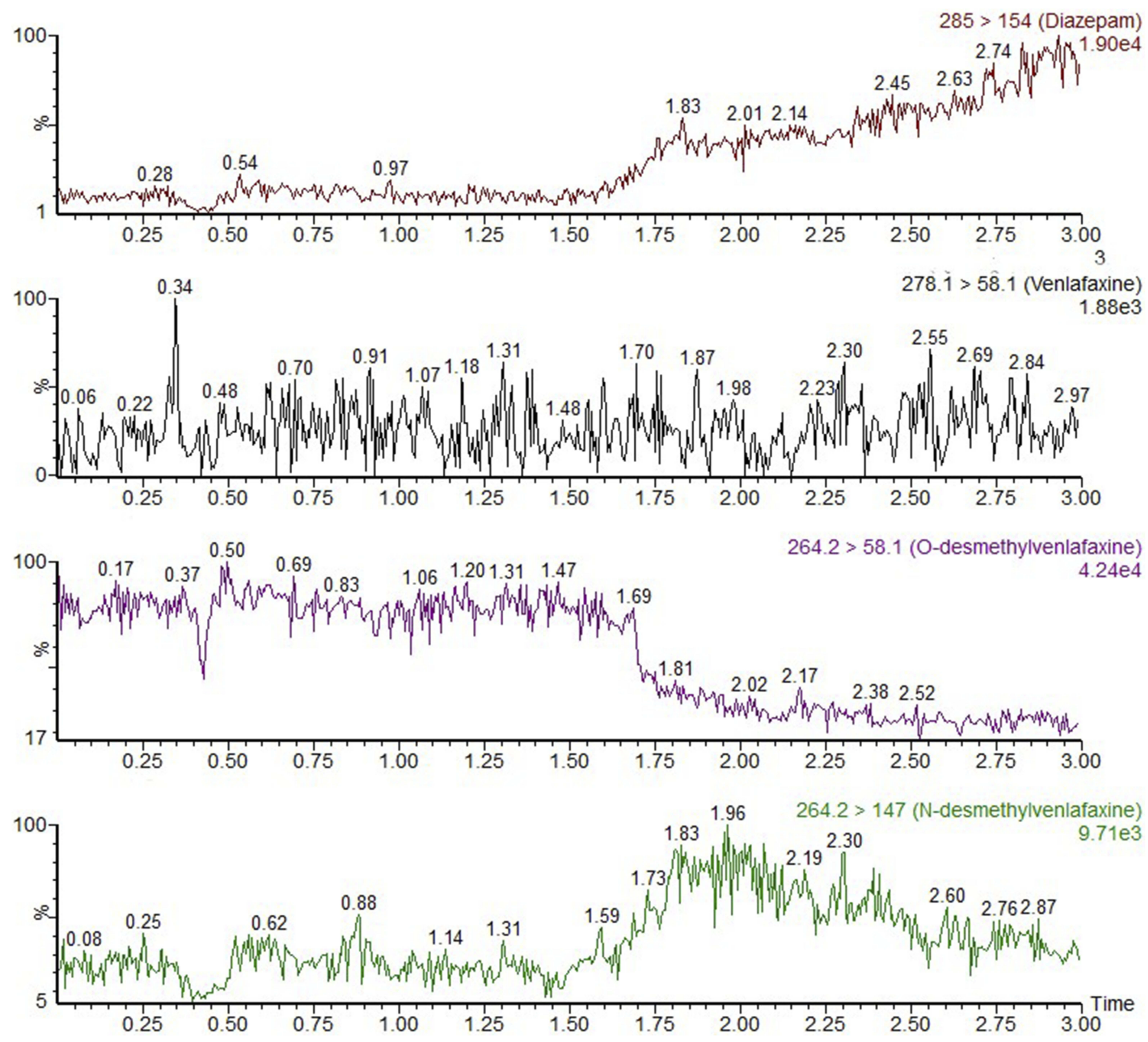

Figure 3 Chromatograms of venlafaxine and its metabolite. (A) Blank plasma; (B) blank plasma spiked with venlafaxine, ODV, NDV and internal standard; (C) beagle sample. 
B
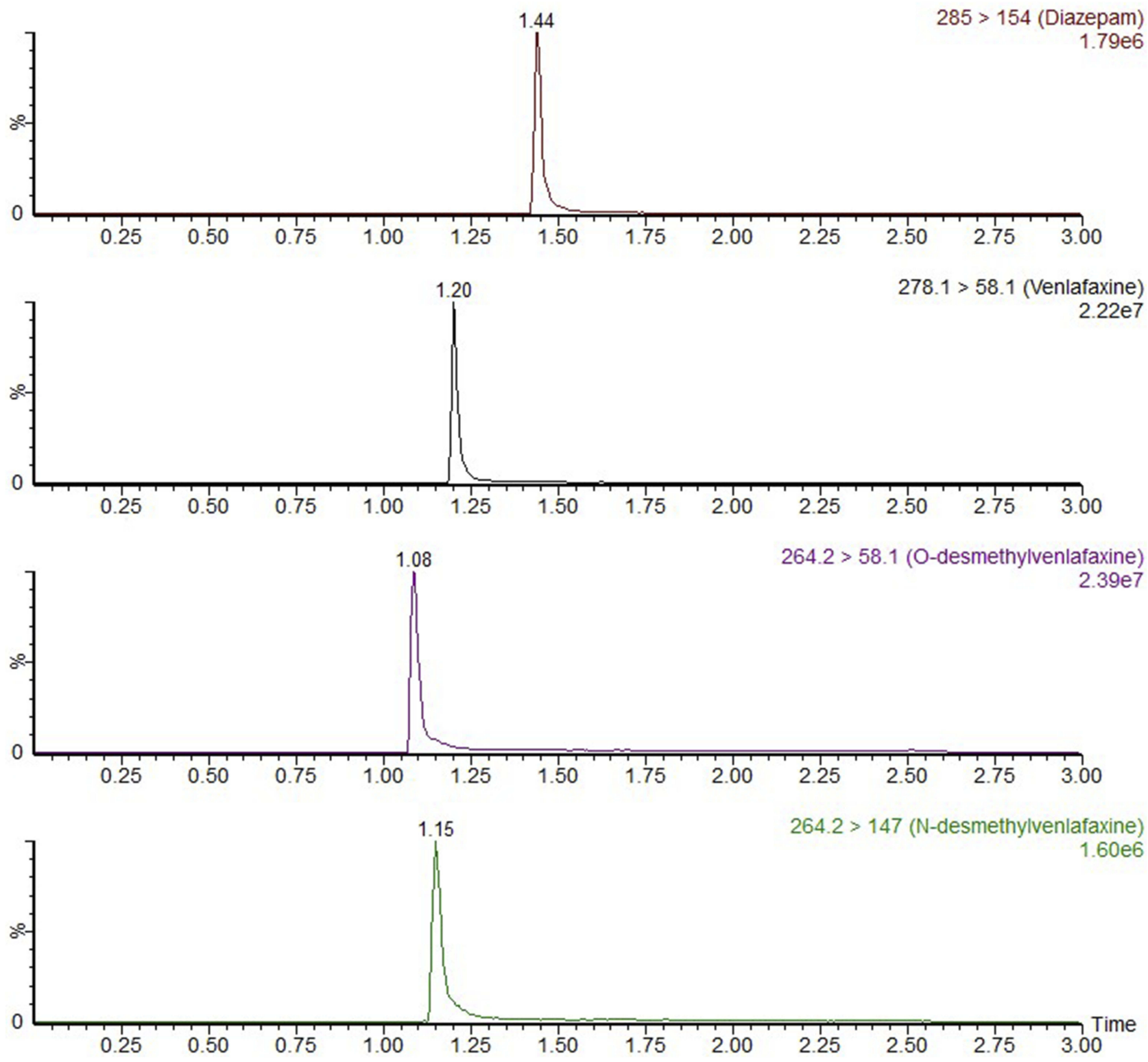

Figure 3 Continued.

and long analysis time (can only detect venlafaxine and its main active metabolite ODV). ${ }^{6}$ This study adopts the method of UPLC-MS/MS and measures the concentration of venlafaxine, ODV and NDV, which is verified by the methodology. This method is in full compliance with the bioassay standard and has a high sensitivity and fast analysis speed, greatly improving the standard of test and reliability, which meets the pharmacokinetic study of venlafaxine. As for IS substance, diazepam was chosen after many preliminary experiments, and venlafaxine, ODV, NDV and diazepam have a good separation and peak shape. At the same time, the endogenous substances in beagle plasma samples do not interfere with them, and so diazepam was chosen as an internal standard to determine the content of venlafaxine and its metabolites. In this experiment, methanol, acetonitrile and ultra-pure water solution were respectively investigated in solvent selection. After UPLC-MS/MS analysis, it was found that the separation degree of methanol after dissolution was the best. Therefore, venlafaxine, ODV and NDV were separated by methanol.

As Tables 6-8 show, the difference between the three groups was statistically significant $(\mathrm{P}<0.05)$. Danzhi Xiaoyao pills promoted the metabolism of venlafaxine, and so the 

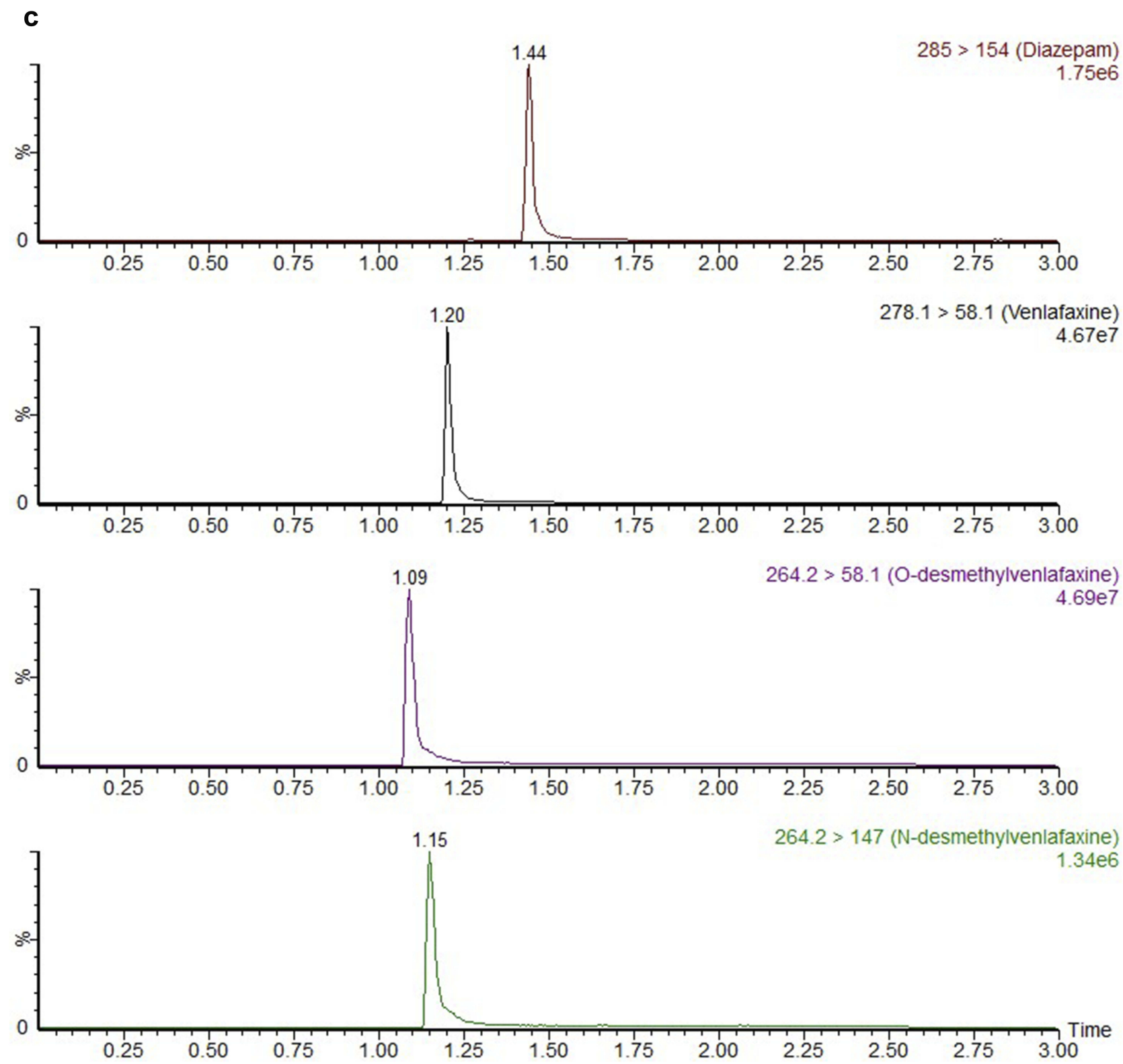

Figure 3 Continued.

blood concentration of its metabolite ODV (the major active metabolite of venlafaxine) and NDV (the minor metabolite of venlafaxine) was also increased. A study has shown that the interaction of traditional Chinese medicine on western medicine mainly affects CYP450. ${ }^{26} \mathrm{CYP} 450$, which is a superfamily of enzymes, is the main phase 1 enzyme system for the metabolism of herbal substance. ${ }^{27}$ In previous studies, CYP1A2, CYP2C9, CYP2C19, CYP2D6, and CYP3A4 (all belong to CYP450) have been proven that they are the major actors to metabolize a vast majority of widely known drugs. ${ }^{28,29}$ In recent years, a number of studies have shown that the active ingredients in Danzhi Xiaoyao pill can affect the activity of CYP2D6 or CYP3A4. Ying Cheng et $\mathrm{a}^{30}$ showed that Radix Bupleuri and vinegar-baked Radix Bupleuri had strong induction effects on the CYP2E1, CYP2D6 and CYP3A4. Jing Wang et $\mathrm{al}^{31}$ found that high-dose bupleurum injection can induce the expression of CYP3A4 protein in rats. Venlafaxine is metabolized to ODV by CYP2D6 and NDV by CYP3A4, and therefore we speculate that Danzhi Xiaoyao pill may induce venlafaxine metabolism by affecting the activity of CYP2D6 or CYP3A4.

In conclusion, based on the results of our research, we suspect that the mechanism of action of Danzhi Xiaoyao pill on venlafaxine may affect CYP450. This study can provide a 
Table I Precision And Accuracy Of Venlafaxine, ODV And NDV In Beagle Plasma $(n=6$, Mean $\pm S D)$

\begin{tabular}{|c|c|c|c|c|c|c|c|}
\hline \multirow[t]{2}{*}{ Analytes } & \multirow[t]{2}{*}{ Added $(\mathrm{ng} / \mathrm{mL})$} & \multicolumn{3}{|l|}{ Intra-Day Precision } & \multicolumn{3}{|l|}{ Inter-Day Precision } \\
\hline & & Detected (ng/mL) & RSD(\%) & RE(\%) & Detected (ng/mL) & RSD(\%) & RE(\%) \\
\hline \multirow[t]{3}{*}{ Venlafaxine } & 2.5 & $2.42 \pm 0.17$ & 6.87 & -3.07 & $2.42 \pm 0.13$ & 5.23 & -3.07 \\
\hline & 100 & $98.94 \pm 6.73$ & 6.80 & -1.06 & $99.94 \pm 1.92$ & 1.92 & -0.06 \\
\hline & 1500 & $|498.87 \pm| 4.54$ & 0.97 & -0.08 & $1503.00 \pm 8.54$ & 0.57 & 0.20 \\
\hline \multirow[t]{3}{*}{ ODV } & 2.5 & $2.49 \pm 0.14$ & 5.59 & -0.40 & $2.47 \pm 0.08$ & 3.10 & -1.12 \\
\hline & 100 & $100.65 \pm 0.97$ & 0.96 & 0.65 & $101.42 \pm 0.51$ & 0.51 & 1.42 \\
\hline & 1500 & $|50| .75 \pm 6.8 \mid$ & 0.45 & 0.12 & $1495.23 \pm 7.46$ & 0.50 & -0.32 \\
\hline \multirow[t]{3}{*}{ NDV } & 0.25 & $0.25 \pm 0.01$ & 2.97 & -0.53 & $0.24 \pm 0.0 \mathrm{I}$ & 4.53 & -5.24 \\
\hline & 10 & $10.32 \pm 0.48$ & 4.66 & 3.20 & $10.07 \pm 0.25$ & 2.50 & 0.69 \\
\hline & 150 & $152.29 \pm 3.66$ & 2.40 & 1.53 & $|50.7| \pm 1.59$ & 1.05 & 0.47 \\
\hline
\end{tabular}

Table 2 Recovery And Matrix Effects For Venlafaxine, ODV, NDV And IS Of Quality Control Samples In Beagle Plasma $(n=6$, Mean \pm SD)

\begin{tabular}{|c|c|c|c|c|c|}
\hline \multirow[t]{2}{*}{ Analytes } & \multirow[t]{2}{*}{ Added (ng/mL) } & \multicolumn{2}{|l|}{ Recovery (\%) } & \multicolumn{2}{|l|}{ ME(\%) } \\
\hline & & Detected $(\mathrm{ng} / \mathrm{mL})$ & RSD(\%) & Detected (ng/mL) & RSD(\%) \\
\hline \multirow[t]{3}{*}{ Venlafaxine } & 2.5 & $85.76 \pm 2.64$ & 3.08 & $100.94 \pm 4.45$ & 4.40 \\
\hline & 100 & $84.47 \pm 4.30$ & 5.09 & $101.53 \pm 3.01$ & 2.96 \\
\hline & 1500 & $80.53 \pm 2.39$ & 2.97 & $99.49 \pm 2.21$ & 2.22 \\
\hline \multirow[t]{3}{*}{ ODV } & 2.5 & $87.43 \pm 4.90$ & 5.60 & $101.30 \pm 4.32$ & 4.18 \\
\hline & 100 & $84.92 \pm 3.62$ & 4.26 & $99.83 \pm 3.67$ & 3.67 \\
\hline & 1500 & $98.48 \pm 2.96$ & 3.00 & $98.91 \pm 2.46$ & 2.49 \\
\hline \multirow[t]{3}{*}{ NDV } & 0.25 & $83.45 \pm 4.18$ & 5.01 & $99.49 \pm 4.15$ & 4.17 \\
\hline & 10 & $81.66 \pm 3.85$ & 4.72 & $101.88 \pm 3.11$ & 3.06 \\
\hline & 150 & $85.24 \pm 2.56$ & 3.01 & $99.83 \pm 2.53$ & 2.53 \\
\hline IS & 50 & $91.03 \pm 5.88$ & 6.46 & $100.10 \pm 3.69$ & 3.68 \\
\hline
\end{tabular}

Table 3 Stability For Venlafaxine In 4 Different Storage And Temperature Conditions $(n=6$, Mean \pm SD)

\begin{tabular}{|c|c|c|c|c|}
\hline Storage Conditions & Added (ng/mL) & Detected (ng/mL) & RSD(\%) & RE(\%) \\
\hline \multirow{3}{*}{ Room temperature, $4 \mathrm{hrs}$} & 2.5 & $2.54 \pm 0.17$ & 6.54 & 1.40 \\
\hline & 100 & $98.15 \pm 2.72$ & 2.77 & -1.85 \\
\hline & 1500 & $15|2.03 \pm 4| .36$ & 2.74 & 0.80 \\
\hline \multirow[t]{3}{*}{$4^{\circ} \mathrm{C}, 24 \mathrm{hrs}$} & 2.5 & $2.48 \pm 0.15$ & 6.15 & -0.80 \\
\hline & 100 & $102.08 \pm 4.28$ & 4.20 & 2.08 \\
\hline & 1500 & $1490.78 \pm 38.56$ & 2.59 & -0.61 \\
\hline \multirow[t]{3}{*}{ Three freeze-thaw cycles } & 2.5 & $2.35 \pm 0.15$ & 6.23 & -5.87 \\
\hline & 100 & $101.46 \pm 5.30$ & 5.22 & 1.46 \\
\hline & 1500 & $|479.6| \pm 46.9 \mid$ & 3.17 & -1.36 \\
\hline \multirow[t]{3}{*}{$-20^{\circ} \mathrm{C}, 4$ weeks } & 2.5 & $2.30 \pm 0.12$ & 5.05 & -8.13 \\
\hline & 100 & $96.35 \pm 2.60$ & 2.70 & -3.65 \\
\hline & 1500 & $|468.5| \pm 36.93$ & 2.52 & -2.10 \\
\hline
\end{tabular}


Table 4 Stability For ODV In 4 Different Storage And Temperature Conditions $(n=6$, Mean \pm SD)

\begin{tabular}{|c|c|c|c|c|}
\hline Storage Conditions & Added (ng/mL) & Detected (ng/mL) & RSD(\%) & RE(\%) \\
\hline \multirow[t]{3}{*}{ Room temperature, $4 \mathrm{hrs}$} & 2.5 & $2.54 \pm 0.07$ & 2.95 & 1.53 \\
\hline & 100 & $|00.86 \pm 2.4|$ & 2.39 & 0.86 \\
\hline & 1500 & $|504.01 \pm 1| .07$ & 0.74 & 0.27 \\
\hline \multirow[t]{3}{*}{$4{ }^{\circ} \mathrm{C}, 24 \mathrm{hrs}$} & 2.5 & $2.56 \pm 0.09$ & 3.42 & 2.27 \\
\hline & 100 & $102.07 \pm 5.81$ & 5.69 & 2.07 \\
\hline & 1500 & $1493.00 \pm 25.55$ & 1.71 & -0.47 \\
\hline \multirow[t]{3}{*}{ Three freeze-thaw cycles } & 2.5 & $2.56 \pm 0.14$ & 5.31 & 2.47 \\
\hline & 100 & $95.60 \pm 3.89$ & 4.07 & -4.40 \\
\hline & 1500 & $1503.85 \pm 1 \mid .20$ & 0.75 & 0.26 \\
\hline \multirow[t]{3}{*}{$-20^{\circ} \mathrm{C}, 4$ weeks } & 2.5 & $2.61 \pm 0.15$ & 5.81 & 4.27 \\
\hline & 100 & $102.61 \pm 5.28$ & 5.15 & 2.61 \\
\hline & 1500 & $1490.73 \pm 20.42$ & 1.37 & -0.62 \\
\hline
\end{tabular}

Table 5 Stability For NDV In 4 Different Storage And Temperature Conditions $(n=6$, Mean \pm SD)

\begin{tabular}{|c|c|c|c|c|}
\hline Storage Conditions & Added (ng/mL) & Detected (ng/mL) & RSD(\%) & RE(\%) \\
\hline \multirow[t]{3}{*}{ Room temperature, $4 \mathrm{hrs}$} & 0.25 & $0.25 \pm 0.02$ & 6.65 & -2.00 \\
\hline & 10 & $9.54 \pm 0.40$ & 4.17 & -4.62 \\
\hline & 150 & $150.23 \pm 7.45$ & 4.96 & 0.16 \\
\hline \multirow[t]{3}{*}{$4^{\circ} \mathrm{C}, 24 \mathrm{hrs}$} & 0.25 & $0.24 \pm 0.01$ & 5.04 & -3.47 \\
\hline & 10 & $10.28 \pm 0.51$ & 4.93 & 2.76 \\
\hline & 150 & $148.52 \pm 6.18$ & 4.16 & -0.99 \\
\hline \multirow[t]{3}{*}{ Three freeze-thaw cycles } & 0.25 & $0.25 \pm 0.01$ & 5.87 & -0.67 \\
\hline & 10 & $9.74 \pm 0.80$ & 8.18 & -2.58 \\
\hline & 150 & $148.33 \pm 9.07$ & 6.12 & -1.12 \\
\hline \multirow[t]{3}{*}{$-20^{\circ} \mathrm{C}, 4$ weeks } & 0.25 & $0.25 \pm 0.02$ & 7.16 & -0.73 \\
\hline & 10 & $|0.30 \pm 0.7|$ & 6.93 & 3.62 \\
\hline & 150 & $147.79 \pm 5.35$ & 3.62 & -1.47 \\
\hline
\end{tabular}

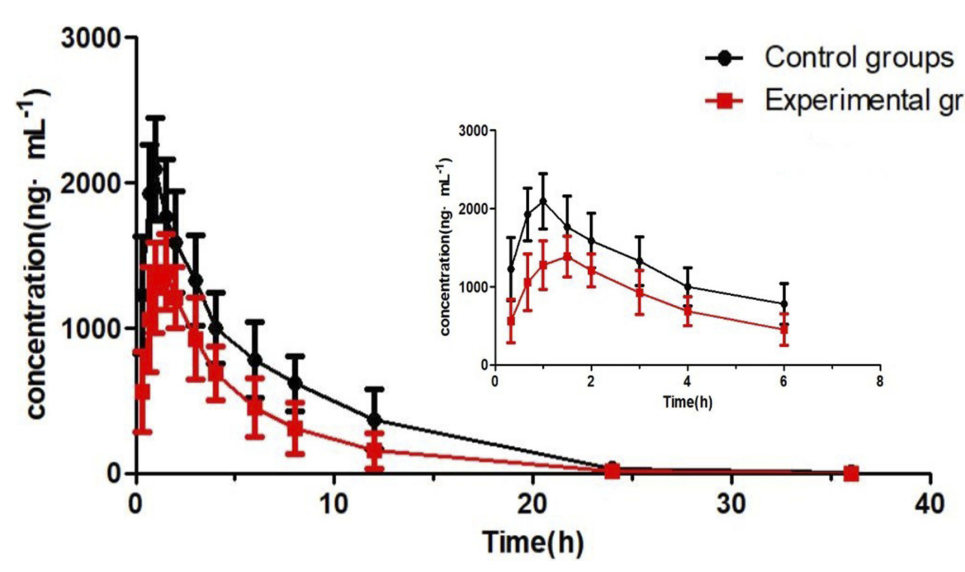

Figure 4 Mean plasma concentration-time curves of venlafaxine after oral administration of $10.28 \mathrm{mg} / \mathrm{kg}$ venlafaxine hydrochloride tablets in beagles $(\mathrm{n}=6$, mean $\pm \mathrm{SD})$. 


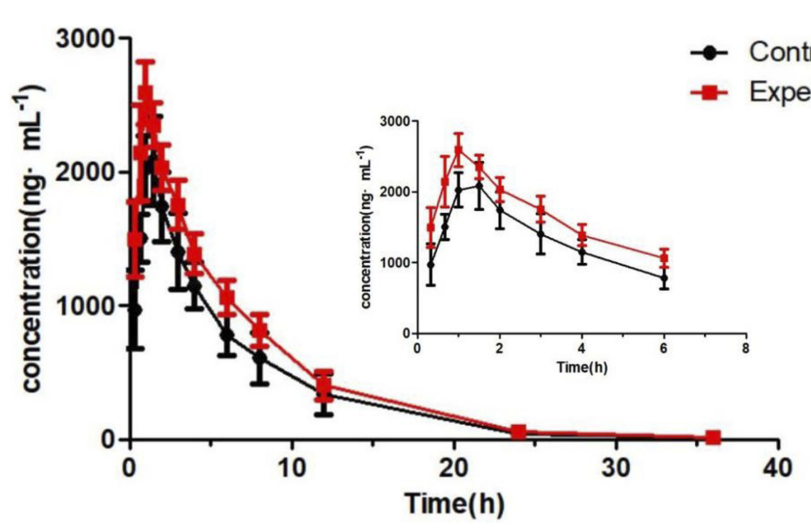

Figure 5 Mean plasma concentration-time curves of ODV after oral administration of $10.28 \mathrm{mg} / \mathrm{kg}$ venlafaxine hydrochloride tablets in beagles $(\mathrm{n}=6$, mean \pm SD).

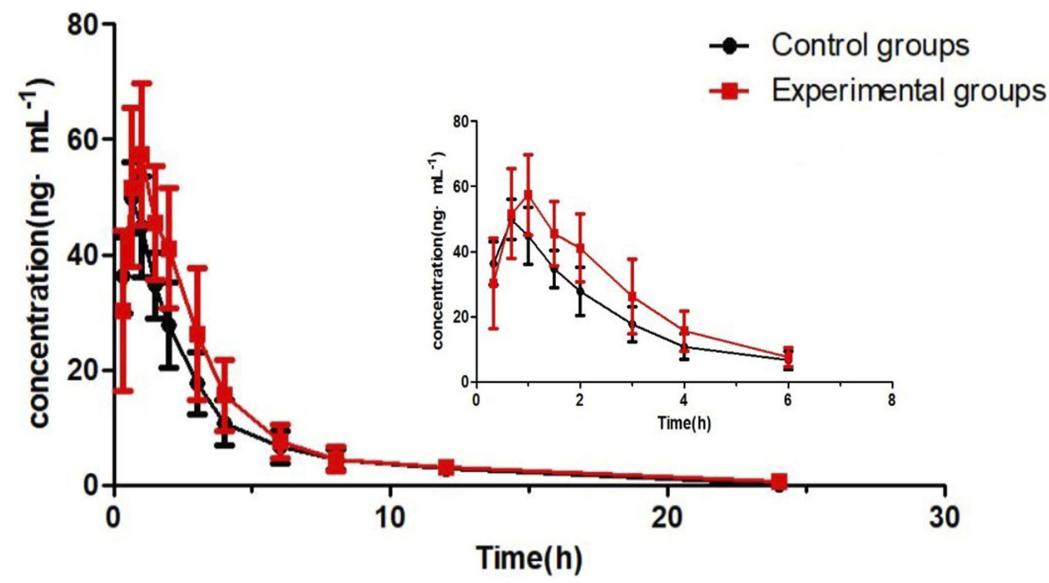

Figure 6 Mean plasma concentration-time curves of NDV after oral administration of $10.28 \mathrm{mg} / \mathrm{kg}$ venlafaxine hydrochloride tablets in beagles $(\mathrm{n}=6$, mean \pm SD).

Table 6 Pharmacokinetic Parameters Of Venlafaxine After Oral Administration Of $10.28 \mathrm{mg} / \mathrm{kg}$ Venlafaxine In Beagles $(\mathrm{n}=6$, Mean \pm SD)

\begin{tabular}{|l|l|l|}
\hline Parameters & Control Groups & Experimental Groups \\
\hline $\mathrm{t}_{\mathrm{I} / 2}(\mathrm{hrs})$ & $4.35 \pm 0.82$ & $3.27 \pm 0.63^{*}$ \\
$\mathrm{~T}_{\max }(\mathrm{hrs})$ & $0.97 \pm 0.30$ & $1.42 \pm 0.49 * *$ \\
$\mathrm{MRT}_{(0-\mathrm{t})}(\mathrm{hrs})$ & $6.16 \pm 0.96$ & $5.14 \pm 1.22$ \\
$\mathrm{MRT}_{(0-\infty)}(\mathrm{hrs})$ & $6.29 \pm 1.08$ & $5.17 \pm 1.24$ \\
$\mathrm{C}_{\max }(\mathrm{ng} / \mathrm{mL})$ & $2267.26 \pm 252.89$ & $1542.64 \pm 190.73^{*}$ \\
$\mathrm{CL}_{\mathrm{z}} / \mathrm{F}(\mathrm{L} / \mathrm{h} / \mathrm{kg})$ & $0.76 \pm 0.22$ & $1.32 \pm 0.3 \mathrm{I}^{* *}$ \\
$\mathrm{AUC}_{(0-\mathrm{t})}(\mathrm{ng} \cdot \mathrm{h} / \mathrm{mL})$ & $13,875.79 \pm 3569.69$ & $7993.16 \pm 2157.76^{* *}$ \\
$\mathrm{AUC}_{(0-\infty)}(\mathrm{ng} \cdot \mathrm{h} / \mathrm{mL})$ & $13,934.79 \pm 3609.23$ & $8001.91 \pm 2167.58^{* *}$ \\
\hline
\end{tabular}

Notes: Compared with venlafaxine group: $* \mathrm{P}<0.05, * * \mathrm{P}<0.01$.

scientific basis for clinical treatment of depression with Danzhi Xiaoyao pill and venlafaxine. But due to the complex composition of traditional Chinese medicine and a lot of targets, the mechanism needs further research.

\section{Conclusion}

This experiment successfully established an UPLC-MS/MS method for simultaneous determination of venlafaxine and its major active metabolite ODV and minor metabolite NDV in beagles. The UPLC-MS/MS method was used for the determination of venlafaxine and its metabolites in beagle plasma with high specificity, sensitivity and rapid detection time, which met the requirements of pharmacokinetic guidelines.

The results showed that Danzhi Xiaoyao pill could reduce the plasma exposure of venlafaxine and increase 
Table 7 Pharmacokinetic Parameters Of ODV After Oral Administration Of $10.28 \mathrm{mg} / \mathrm{kg}$ Venlafaxine In Beagles $(\mathrm{n}=6, \mathrm{Mean} \pm \mathrm{SD}$ )

\begin{tabular}{|l|l|l|}
\hline Parameters & Control Groups & Experimental Groups \\
\hline $\mathrm{t}_{\mathrm{I} / 2}(\mathrm{hrs})$ & $4.56 \pm 0.89$ & $4.5 \mathrm{I} \pm 0.69$ \\
$\mathrm{~T}_{\max }(\mathrm{hrs})$ & $1.33 \pm 0.26$ & $1.03 \pm 0.27^{*}$ \\
$\mathrm{MRT}_{(0-\mathrm{t})}(\mathrm{hrs})$ & $6.28 \pm 0.98$ & $6.38 \pm 0.57$ \\
$\mathrm{MRT}_{(0-\infty)}(\mathrm{hrs})$ & $6.51 \pm 1.17$ & $6.61 \pm 0.59$ \\
$\mathrm{C}_{\max }(\mathrm{ng} / \mathrm{mL})$ & $2253.80 \pm 215.8 \mathrm{I}$ & $2721.37 \pm 118.20^{*}$ \\
$\mathrm{CL}_{\mathrm{z}} / \mathrm{F}(\mathrm{L} / \mathrm{h} / \mathrm{kg})$ & $0.76 \pm 0.16$ & $0.59 \pm 0.06^{*}$ \\
$\mathrm{AUC}_{(0-\mathrm{t})}(\mathrm{ng} \mathrm{h} / \mathrm{mL})$ & $13,888.24 \pm 27 / 4.73$ & $17,454.69 \pm 1854.58^{*}$ \\
$\mathrm{AUC}_{(0-\infty)}(\mathrm{ng} \mathrm{h} / \mathrm{mL})$ & $13,974.99 \pm 2784.04$ & $17,539.44 \pm 1894.29 *$ \\
\hline
\end{tabular}

Notes: Compared with venlafaxine group: $* \mathrm{P}<0.05$.

Table 8 Pharmacokinetic Parameters Of NDV After Oral Administration Of $10.28 \mathrm{mg} / \mathrm{kg}$ Venlafaxine $\ln$ Beagles $(\mathrm{n}=6, \mathrm{Mean} \pm$ SD)

\begin{tabular}{|l|l|l|}
\hline Parameters & Control Groups & Experimental Groups \\
\hline $\mathrm{t}_{\mathrm{I} / 2}(\mathrm{hrs})$ & $4.07 \pm 0.88$ & $4.75 \pm 1.52$ \\
$\mathrm{~T}_{\max }(\mathrm{hrs})$ & $0.73 \pm 0.14$ & $1.03 \pm 0.27^{* *}$ \\
$\mathrm{MRT}_{(0-\mathrm{t})}(\mathrm{hrs})$ & $4.06 \pm 0.44$ & $4.15 \pm 0.75$ \\
$\mathrm{MRT}_{(0-\infty)}(\mathrm{hrs})$ & $4.35 \pm 0.53$ & $4.75 \pm 1.21$ \\
$\mathrm{C}_{\max }(\mathrm{ng} / \mathrm{mL})$ & $50.98 \pm 5.76$ & $58.74 \pm 12.33$ \\
$\mathrm{CL} / \mathrm{F}(\mathrm{L} / \mathrm{h} / \mathrm{kg})$ & $57.45 \pm 10.35$ & $47.27 \pm 10.10$ \\
$\mathrm{AUC}_{(0-\mathrm{t})}(\mathrm{ng} \mathrm{h} / \mathrm{mL})$ & $177.36 \pm 34.78$ & $216.22 \pm 51.85^{*}$ \\
$\mathrm{AUC}_{(0-\infty)}(\mathrm{ng} \mathrm{h} / \mathrm{mL})$ & $179.26 \pm 34.94$ & $220.68 \pm 51.4 I^{*}$ \\
\hline
\end{tabular}

Notes: Compared with venlafaxine group: $* \mathrm{P}<0.05, * * \mathrm{P}<0.01$.

the content of ODV and NDV, meaning that Danzhi Xiaoyao pills can influence the metabolism of venlafaxine in beagles. Based on the possibility of this result, it is recommended to adjust the dose when the two drugs were combined in the clinical practice, and this study should be considered significant in guiding clinical treatment.

\section{Acknowledgments}

We appreciate the contribution of the members participating in this study. We also would like to thank The First Affiliated Hospital of WenZhou Medical University for supporting the equipment in this work.

\section{Author Contributions}

Xiang-jun Qui conceived and designed the experiments. Yong-liang Zhu conducted the experiments and drafted the paper. Shuang-long Li, Ke-li Chen, Kun-peng Ma, De-qian $\mathrm{Wu}$ conducted part experiments and analyzed the data. All authors contributed to data analysis, drafting or revising the article, gave final approval of the version to be published, and agreed to be accountable for all aspects of the work.

\section{Disclosure}

The authors report no conflicts of interest in this work.

\section{References}

1. Smith K. Mental health: a world of depression. Nature. 2014;515 (7526): 181. doi:10.1038/515180a

2. Mamdani M, Rochon PA, Juurlink DN, et al. Observational study of upper gastrointestinal haemorrhage in elderly patients given selective cyclo-oxygenase-2 inhibitors or conventional non-steroidal anti-inflammatory drugs. BMJ. 2002;325(7365):624. doi:10.1136/bmj.325.7365.624

3. Wu LL, Liu Y, Yan C, Pan Y, Su JF, Wu WK. Antidepressant-like effects of fractions prepared from Danzhi-Xiaoyao-San Decoction in rats with chronic unpredictable mild stress: effects on hypothalamic-pituitary-adrenal axis, arginine vasopressin, and neurotransmitters. Evid Based Complement Alternat Med. 2016;2016:6784689. doi:10.1155/2016/ 5040528

4. Watanabe Y, Asami Y, Hirano Y, Kuribayashi K, Itamura R, Imaeda T. Factors impacting the efficacy of venlafaxine extended release 75-225 $\mathrm{mg} /$ day in patients with major depressive disorder: exploratory post hoc subgroup analyses of a randomized, double-blind, placebo-controlled study in Japan. Neuropsychiatr Dis Treat. 2018;14:1261-1272. doi:10.2147/NDT.S146428

5. Petruczynik A, Wroblewski K, Szultka-Mlynska M, et al. Determination of venlafaxine, vilazodone and their main active metabolites in human serum by HPLC-DAD anD HPLC-MS. Acta Pol Pharm. 2017;74(3):765-775.

6. Shen S, Zhang C, Mao Y. Determination of venlafaxine and its active metabolite O-desmethylvenlafaxine in human plasma by HPLC fluorescence. Gen Psychiatry. 2018;31(2):e000010. doi:10.1136/gpsych2018-000010

7. Garcia S, Schuh M, Cheema A, Atwal H, Atwal PS. Palpitations and asthenia associated with venlafaxine in a CYP2D6 poor metabolizer and CYP2C19 intermediate metabolizer. Case Rep Genet. 2017; 2017:6236714. doi:10.1155/2017/6236714 
8. Porazka J, Szalek E, Polom W, et al. Influence of obesity and type 2 diabetes mellitus on the pharmacokinetics of tramadol after single oral dose administration. Eur J Drug Metab Pharmacokinet. 2019;44 (4):579-584. doi:10.1007/s13318-019-00543-1

9. Kingback M, Karlsson L, Zackrisson AL, et al. Influence of CYP2D6 genotype on the disposition of the enantiomers of venlafaxine and its major metabolites in postmortem femoral blood. Forensic Sci Int 2012;214(1-3):124-134. doi:10.1016/j.forsciint.2011.07.034

10. Yang K, Zeng L, Ge J. Exploring the pharmacological mechanism of Danzhi Xiaoyao Powder on ER-positive breast cancer by a network pharmacology approach. Evid Based Complement Alternat Med. 2018;2018:5059743. doi:10.1155/2018/9567061

11. Chen T, Chen F. Clinical observation on 40 cases of qi depression and fire depression treated by ease powder of moutan bark and cape jasmine fruit. China Continuing Med Educ. 2018;33(10):149-151.

12. Yan L,X. Danzhi Xiaoyao powder combined with paroxetine in the treatment of depression. Guangming J Chin Med. 2017;32(16):23912393.

13. Zhang Y, Han M, Liu Z, Wang J, He Q, Liu J. Chinese herbal formula xiao yao san for treatment of depression: a systematic review of randomized controlled trials. Evid Based Complement Alternat Med. 2012;2012:931636.

14. Lun Z. A study on the antidepressant effect of Danzhi Xiaoyao Powder. Afr J Tradit Complement Altern Med. 2014;11(1):205-208.

15. Wang H, Wang C,S. Clinical study of combined treatment of Venlafaxine and Jiuwei Zhenxin Keli for perimenopausal depression anxiety. China Med Herald. 2015;2(3):86-88.

16. Zhou LH, Li H, Zeng ZQ, Chen XD, Deng ZH. Chaihu Shugan Powder combined with venlafaxine for treatment of post - stroke depression. Chin J Integr Med Cardio. 2011;09(11):1330-1332.

17. Zhao J,P. Clinical observation of venlafaxine plus traditional Chinese medicine decoction in the treatment of depression. Guangming $J$ Chin Med. 2019;34(4):608-610.

18. Ding X,P, Zhang X. Observing the clinical efficacy and adverse reactions of Danzhi Xiaoyao Powder in the treatment of depression. Med Inf. 2015;(38):397.

19. Pan Huiping WG. A control study of danzhi xiaoyao san combined with small-dose venlafaxine in the treatment of postpartum depression. J Clin Psychosom Dis. 2013;19(2):119-120, 123.

20. Xiao R. Clinical efficacy of Danzhi Xiaoyao Powders with small dose of venlafaxine for the treatment of postpartumde pression. Chin J Clin Ration Drug Use. 2013;6(36):73-74.
21. Ardakani YH, Foroumadi A, Rouini MR. Development and validation of a rapid HPLC- fluorescence method for simultaneous determination of venlafaxine and its major metabolites in human plasma. Daru. 2010;18(2):97-102.

22. US Food and Drug Administration. Guidance for Indus-try: Bioanalytical Method Validation. Rockville, MD, USA: US Department of Health and Human Services, US FDA, Center for Drug Evaluation and Research; 2018. https://www.fda.gov/regula tory-information/search-fda-guidance-documents/bioanalyticalmethod-validation-guidance-industry. Accessed August 10, 2018.

23. Marszalek D, Goldnik A, Pawinski T, Malek G, Somogi A, Mach A. Simultaneous assay of aripiprazole and its active metabolite in serum by HPLC. Acta Pol Pharm. 2017;74(2):405-411.

24. Taddeo VA, Castillo UG, Martinez ML, et al. Development and validation of an HPLC-PDA method for biologically active quinonemethide triterpenoids isolated from maytenus chiapensis. Medicines. 2019;6(1). doi:10.3390/medicines6010036.

25. Baldania SL, Bhatt KK, Mehta RS, Shah DA, Gandhi TR. RP-HPLC estimation of venlafaxine hydrochloride in tablet dosage forms. Indian J Pharm Sci. 2008;70(1):124-128. doi:10.4103/0250-474X.40350

26. Fasinu PS, Bouic PJ, Rosenkranz B. The inhibitory activity of the extracts of popular medicinal herbs on CYP1A2, 2C9, 2C19 and 3A4 and the implications for herb-drug interaction. Afr J Tradit Complement Altern Med. 2014;11(4):54-61. doi:10.4314/ajtcam.v11i4.9

27. Michielan L, Terfloth L, Gasteiger J, Moro S. Comparison of multilabel and single-label classification applied to the prediction of the isoform specificity of cytochrome p450 substrates. J Chem Inf Model. 2009;49(11):2588-2605. doi:10.1021/ci900299a

28. Rendic S, Guengerich FP. Survey of human oxidoreductases and cytochrome P450 enzymes involved in the metabolism of xenobiotic and natural chemicals. Chem Res Toxicol. 2015;28(1):38-42. doi:10.1021/tx500444e

29. Sun W, Wang Z, Chen R, et al. Influences of anlotinib on cytochrome P450 enzymes in rats using a cocktail method. Biomed Res Int. 2017;2017:3619723. doi:10.1155/2017/3619723

30. Chen Y, Huang Y, Tian Y, Xu L, Liu G,Q, Zhang ZJ. Assessment of the effects of Radix Bupleuri and vinegar-baked Radix Bupleuri on cytochrome 450 activity by a six-drug cocktail approach. Chin J Nat Med. 2013;11(3):302-308. doi:10.1016/S1875-5364(13)60033-3

31. Wang J, Yu H,Y, Guo L, Liu Y, Zhu D,L. Role of cytochrome P450 on the metabolism of injection bupleuri. Chin J Clin Pharmacol Ther. 2007;12(9):1037-1041.

\section{Publish your work in this journal}

Drug Design, Development and Therapy is an international, peerreviewed open-access journal that spans the spectrum of drug design and development through to clinical applications. Clinical outcomes, patient safety, and programs for the development and effective, safe, and sustained use of medicines are a feature of the journal, which has also been accepted for indexing on PubMed Central. The manuscript management system is completely online and includes a very quick and fair peer-review system, which is all easy to use. Visit http://www. dovepress.com/testimonials.php to read real quotes from published authors. 